\title{
A pilot clinical trial of intravesical mitomycin-C and external deep pelvic hyperthermia for non-muscle-invasive bladder cancer.
}

\author{
Brant A Inman \\ Duke University Medical Center \\ Paul R. Stauffer \\ Thomas Jefferson University \\ Oana A Craciunescu \\ Duke University Medical Center \\ Paolo F Maccarini \\ Duke University Medical Center

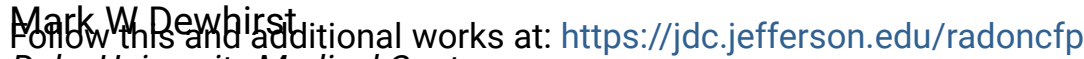 \\ Dilke University Medical Center \\ Part of the Oncology Commons, and the Radiology Commons

\section{Let us know how access to this document benefits you}

\section{Recommended Citation}

Inman, Brant A; Stauffer, Paul R.; Craciunescu, Oana A; Maccarini, Paolo F; Dewhirst, Mark W; and Vujaskovic, Zeljko, "A pilot clinical trial of intravesical mitomycin-C and external deep pelvic hyperthermia for non-muscle-invasive bladder cancer." (2014). Department of Radiation Oncology Faculty Papers. Paper 52.

https://jdc.jefferson.edu/radoncfp/52

This Article is brought to you for free and open access by the Jefferson Digital Commons. The Jefferson Digital Commons is a service of Thomas Jefferson University's Center for Teaching and Learning (CTL). The Commons is a showcase for Jefferson books and journals, peer-reviewed scholarly publications, unique historical collections from the University archives, and teaching tools. The Jefferson Digital Commons allows researchers and interested readers anywhere in the world to learn about and keep up to date with Jefferson scholarship. This article has been accepted for inclusion in Department of Radiation Oncology Faculty Papers by an authorized administrator of the Jefferson Digital Commons. For more information, please contact: JeffersonDigitalCommons@jefferson.edu. 


\section{Authors}

Brant A Inman, Paul R. Stauffer, Oana A Craciunescu, Paolo F Maccarini, Mark W Dewhirst, and Zeljko Vujaskovic 


\title{
A pilot clinical trial of intravesical mitomycin-C and external deep pelvic hyperthermia for non-muscle-invasive bladder cancer
}

\author{
Brant A. Inman ${ }^{1}$, Paul R. Stauffer ${ }^{2}$, Oana Craciunescu ${ }^{3}$, Paolo F. Maccarini ${ }^{3}$, Mark W. \\ Dewhirst $^{3}$, and Zeljko Vujaskovic ${ }^{4}$ \\ ${ }^{1}$ Division of Urology, Duke University Medical Center, Durham, North Carolina \\ ${ }^{2}$ Department of Radiation Oncology, Thomas Jefferson University, Philadelphia, Pennsylvania \\ ${ }^{3}$ Department of Radiation Oncology, Duke University Medical Center, Durham, North Carolina \\ ${ }^{4}$ Department of Radiation Oncology, University of Maryland, Maryland, USA
}

\begin{abstract}
Purpose-This paper aims to evaluate the safety and heating efficiency of external deep pelvic hyperthermia combined with intravesical mitomycin C (MMC) as a novel therapy for non-muscleinvasive bladder cancer (NMIBC).

Materials and methods-We enrolled subjects with bacillus Calmette-Guérin (BCG) refractory NMIBC to an early phase clinical trial of external deep pelvic hyperthermia (using a BSD-2000 device) combined with MMC. Bladders were heated to $42^{\circ} \mathrm{C}$ for $1 \mathrm{~h}$ during intravesical MMC treatment. Treatments were given weekly for 6 weeks, then monthly for 4 months. Heating parameters, treatment toxicity, and clinical outcomes were systematically measured.
\end{abstract}

Results-Fifteen patients were enrolled on the clinical trial. Median age was 66 years and 87\% were male. Median European Organisation for Research and Treatment of Cancer (EORTC) recurrence and progression scores were 6 and 8 , respectively. The full treatment course was attained in $73 \%$ of subjects. Effective bladder heating was possible in all but one patient who could not tolerate the supine position due to lung disease. Adverse events were all minor (grade 2 or less) and no systemic toxicity was observed. The most common adverse effects were Foley catheter pain (40\%), abdominal discomfort (33\%), chemical cystitis symptoms (27\%), and abdominal skin swelling (27\%). With a median follow-up of 3.18 years, $67 \%$ experienced another bladder cancer recurrence (none were muscle invasive) and $13 \%$ experienced an upper tract recurrence.

() 2014 Informa UK Ltd.

Correspondence: Brant A. Inman, MD, Box 2812, Division of Urology, Duke University Medical Center, Durham, NC 27710, USA. Tel: 919-681-8760. Fax: 919-684-5220. brant.inman@ duke.edu.

Declaration of interest

This clinical trial was supported by a grant from the US National Cancer Institute (PO1 CA42745). The authors alone are responsible for the content and writing of the paper. 
Conclusions-External deep pelvic hyperthermia using the BSD-2000 device is a safe and reproducible method of heating the bladder in patients undergoing intravesical MMC. The efficacy of this treatment modality should be explored further in clinical trials.

\section{Keywords}

Bladder cancer; clinical trial; hyperthermia; mitomycin C

\section{Introduction}

Bladder cancer is the fourth most common type of cancer in men and the ninth most common cancer in women in the USA [1]. The most common type of bladder cancer, urothelial carcinoma, originates in cells lining the inside of the bladder and accounts for $\sim 90 \%$ of all bladder cancers. Bladder cancers are staged according to a standard tumour, lymph node, and metastasis (TNM) staging system: Ta - non-invasive, T1 - invasive into lamina propria, T2 - invasive into muscularis propria, T3 - invasive into perivesical fat, and T4 - invasive into adjacent organs. Two broad clinical phenotypes of bladder cancer exist: non-muscle-invasive bladder cancer (NMIBC) (Ta, T1) and muscle invasive bladder cancer (T2, T3, T4) and each are managed differently [2].

A fundamental characteristic of NMIBC is a very high local recurrence rate, ranging from $40-80 \%$, depending on individual prognostic factors. An important goal in managing NMIBC is reducing the risk of bladder cancer recurrences, which can occur repeatedly over many years, leading to multiple surgical interventions and high healthcare costs. The application of intravesical chemotherapy, whether given in the operating room immediately following transurethral tumour resection or adjuvantly using a weekly dosing scheme, has been shown to reduce the recurrence rate of bladder cancer [3,4]. Unfortunately, intravesical chemotherapy does not eliminate the risk of recurrence and at least a third of subjects treated with intravesical chemotherapy will still recur. One strategy that has been shown to increase the efficacy of intravesical chemotherapy is bladder hyperthermia, a treatment where the bladder is heated to enhance the effectiveness of the chemotherapeutic agent filling the bladder [5-7]. Hyperthermia has numerous effects on the tumour micro-environment [8], but the most important known effect in bladder cancer is that it makes existing bladder chemotherapies more effective. Specifically, a number of European clinical trials have shown that moderate hyperthermia $\left(42-44{ }^{\circ} \mathrm{C}\right)$ improves the efficacy of intravesical mitomycin $\mathrm{C}$ (MMC), the most commonly used intravesical chemotherapy agent [9]. Combined hyperthermia and mitomycin $\mathrm{C}$ has not, to our knowledge, been studied clinically in North America and the current study is the first to do so.

Bladder heating can be achieved in different ways, including by radiofrequency-emitting intravesical catheters, by circulation of externally heated chemotherapy fluid into the bladder, by exciting intravesical magnetic nanoparticles within a magnetic field, and with external deep pelvic radiofrequency transmission [9]. External deep pelvic hyperthermia has been used in combination with radiation therapy to treat pelvic malignancies and has been shown to be an effective of heating pelvic organs [10], but it has never been employed to our knowledge in combination with intravesical therapy for treating bladder cancer. Deep pelvic 
hyperthermia is accomplished in the current clinical trial using a phased array of external radiofrequency antennas that deposit energy within the pelvis and are focused primarily on the bladder. In this clinical trial, we explored intravesical mitomycin $\mathrm{C}$ combined with external deep pelvic hyperthermia for the treatment of bacillus Calmette-Guérin (BCG) refractory NMIBC as a novel way of combining hyperthermia with intravesical therapy. We hypothesised that this treatment regimen would result in effective bladder heating and would be tolerable to the patient and would occur with minimal toxicity.

\section{Patients and methods}

\section{Subjects}

This clinical trial was designed to assess the safety and tolerability of external deep pelvic hyperthermia combined with intravesical MMC to treat BCG refractory NMIBC. Eligibility criteria included age $\geq 18$ years, urothelial carcinoma with TNM stage Ta, T1, or Tis, a minimum 2-week interval since transurethral resection of bladder tumour (TURBT), and an Eastern Clinical Oncology Group (ECOG) performance status $\mathcal{\imath}$. Additionally, subjects were required to have completed a 6-week induction course of BCG prior to their most recent bladder cancer recurrence or be intolerant of BCG. Subjects were excluded if any of the following were present: history of pelvic radiation, pregnancy or breastfeeding, bleeding diathesis, hypersensitivity to MMC, pacemaker or related electrical devices, hip prostheses or other implanted pelvic hardware, uncontrolled hypertension, severe respiratory disease that precluded supine positioning or abdominal compression, or severe peripheral neuropathy. All subjects underwent urine cytology, cystoscopy and CT urography within 8 weeks of enrolment to rule out prevalent upper urinary tract, bladder, or urethral tumours. The protocol was approved by the Duke Institutional Review Board (IRB) and registered at www.clinicaltrials.gov (NCT00734994) under IDE G030263. Eligible subjects provided written informed consent and accrual occurred between November 2008 and August 2010.

\section{Intravesical therapy and treatment schedule}

An induction course of intravesical MMC ( $40 \mathrm{mg}$ diluted in $40 \mathrm{~mL}$ of sterile water) was administered once weekly for 6 weeks [11]. The MMC dwell time was at least 60 min but no more than $120 \mathrm{~min}$ in duration, of which $40 \mathrm{~min}$ but no more than $60 \mathrm{~min}$ had to occur at a temperature of $42^{\circ} \pm 2{ }^{\circ} \mathrm{C}$. Cystoscopy and urine cytology tests were performed 6 weeks after completion of induction and, if no evidence of bladder cancer recurrence was noted in either test, maintenance MMC was administered consisting of monthly intravesical MMC given for an additional 4 months $[12,13]$. Therefore, a maximum of 10 treatments of combination MMC and hyperthermia was possible under the protocol. At each intravesical treatment, an $18 \mathrm{~F} 3$-way Foley catheter was inserted into the bladder, the bladder drained of urine, a bladder thermistor placed, MMC instilled, and bladder heating started.

\section{External deep pelvic hyperthermia}

Deep pelvic hyperthermia was achieved with a BSD-2000 device with Sigma-Ellipse or Sigma 60 applicator (BSD Medical, Salt Lake City, UT). Using either applicator, the system consists of an external phased array of four twin dipole antennas mounted concentrically around the torso and coupled with a distilled water bolus to deliver radiofrequency waves 
within a range of $80-120 \mathrm{MHz}$ to produce a steerable focal region within the pelvis. A planning CT scan was obtained prior to treatment and device settings determined using a hyperthermia planning system. The treatment goal was an intravesical temperature of $42^{\circ} \pm$ $2{ }^{\circ} \mathrm{C}$ that was to be maintained for 40-60 min and initial applicator settings were manually adjusted during treatment based on real-time input from skin surface and intracavitary (bladder and rectum) temperature sensors. Full details of the thermal dosimetry and treatment planning methods used in this clinical trial are described elsewhere [6].

\section{Bladder surveillance and treatment toxicity assessment}

Subjects were followed according to NCCN Clinical Practice Guidelines in Oncology for Bladder Cancer (version 2.2008, www.nccn.org) for high risk NMIBC. This consisted of cystoscopy and urine cytology every 3 months for 2 years, then every 6 months for 2 years, then annually thereafter. Routine upper tract imaging was not required by the study protocol but was generally performed if recurrent disease was noted in the bladder or if urine cytology was positive in a subject with negative cystoscopy. All suspicious lesions detected during surveillance were biopsied to confirm local disease recurrence, which was defined as the histological presence of urothelial carcinoma in the bladder. Recurrence of urothelial carcinoma in the upper urinary tracts or urethra was also recorded and was considered nonlocal disease recurrence. Progression was defined as the development of muscle-invasive bladder cancer or urothelial carcinoma metastases to lymph nodes or other solid organs. Recurrent tumours were graded using the World Health Organization/International Society of Urological Pathology (ISUP) system and staged with the 2010 TNM system $[2,14]$. Treatment toxicity was assessed at each treatment session and at each clinical surveillance visit and graded using the Common Terminology Criteria for Adverse Events (CTCAE), version 3.0. Toxicities occurring outside of routine follow-up were also captured.

\section{Statistical methods}

This was a pilot clinical trial to assess the safety and feasibility of combining deep external pelvic hyperthermia to intravesical MMC. The primary objective was to determine the ability of the BSD-2000 device to heat the bladder to the desired temperature and to determine the incidence of treatment-related toxicity. The secondary objective was to determine the cumulative incidence of bladder cancer recurrence and progression at 2 years, and as such, all subjects were followed until recurrence or until a minimum of two posttreatment years had elapsed. The statistical plan called for up to 18 subjects to be enrolled in the trial for a total of 15 evaluable subjects. Clinical variables were described using proportions if categorical, and using medians and their interquartile range if continuous. Bladder cancer recurrences and the occurrence of radical cystectomy were measured using cumulative incidence functions [15]. Statistical analyses were done using R 3.0.1 with packages cmprsk and survival installed [16].

\section{Results}

A total of 18 subjects were approached for enrolment in the clinical trial. Of these, 15 met all eligibility criteria and consented to the clinical trial. Baseline clinical characteristics of the study population are shown in Table I. As the table demonstrates, the study population 
consisted of subjects that had experienced multiple prior transurethral bladder cancer resections and all had experienced at least one recurrence following prior BCG therapy. High risk features for recurrence and/or progression - such as the presence of CIS, T1 lamina propria invasion, high grade cytology, or an elevated prior recurrence rate - were present in all subjects. Using the EORTC bladder cancer risk prediction tools [17], 86\% of subjects were deemed to be at high or very high risk of recurrence and $80 \%$ were at high or very high risk of progression.

The full treatment course (six induction sessions + four maintenance sessions) was achieved in $11(73 \%)$ subjects. One subject withdrew from the study after undergoing a single attempt at treatment due to an inability to tolerate the supine position as a result of severe chronic obstructive pulmonary disease. Three subjects received the full induction course but were withdrawn from the study prior to receiving all four maintenance sessions due to cancer recurrences detected at the first post-induction surveillance cystoscopy. The heating time required to achieve $42{ }^{\circ} \mathrm{C}$ was $10-15 \mathrm{~min}$.

Adverse events are summarised in Table II. The most common adverse events were minor urethral discomfort from Foley catheter placement (40\%), minor abdominal discomfort from the hyperthermia device (33\%), irritative urinary symptoms from chemical cystitis (27\%), and heat-induced minor swelling of the abdominal skin (27\%). No grade 3 or greater toxicities were observed and no subject discontinued therapy due to adverse events.

With a median follow-up from study enrolment to last visit of 3.18 years, $10(67 \%)$ subjects experienced recurrent bladder cancer, with a median time to recurrence of 15.4 months, but none of these recurrences consisted of progression events to detrusor muscle invasion. The cumulative incidence of recurrences is shown in Figure 1(A). Of the 10 subjects that recurred with bladder cancer, six $(60 \%)$ underwent radical cystectomy at a median time of 20.1 months from study enrolment. Pathological stage at cystectomy was pTis in five subjects, pT1 in one subject, and pelvic nodes were negative in all patients (median node count $=15)$. The cumulative incidence of cystectomy is shown in Figure 1(B). Three subjects with recurrent bladder cancer (30\%) refused cystectomy and underwent alternative intravesical regimens and none has experienced disease progression. Two subjects (13\%) developed upper urinary tract recurrences and these occurred at a median time from enrolment of 18.7 months. Both of these individuals were treated for their upper urinary tract cancer but ultimately developed metastases and died from their disease. One patient (7\%) died from causes unrelated to cancer.

\section{Discussion}

Patients with BCG-refractory NMIBC are in a difficult conundrum [18]. On the one hand, their disease state does not normally carry an imminent risk of metastasis and death, but on the other hand, it can progress (usually over years) into a muscle-invasive disease state that certainly does carry this risk. The most widely accepted treatment for BCG-refractory NMIBC that reduces the risk of progression and results in a very high probability of cure is radical cystectomy. Unfortunately, radical cystectomy is a morbid surgical procedure that is associated with permanent quality of life changes and also a non-negligible treatment-related 
mortality rate [19]. Additionally, it is costly and has a very high perioperative complication rate. Patients and their doctors must therefore decide between taking a risky treatment that causes some degree of permanent disability and loss of quality of life but that is likely curative, or choose to observe the cancer and run the risk of it progressing to a state where it is no longer curable.

This difficult clinical dilemma is why there is a clear need for less invasive alternatives to radical cystectomy for patients with NMIBC that continues to recur despite standard firstline BCG therapy. In this respect, second-line intravesical therapies are certainly the most commonly explored alternatives to radical cystectomy. Mitomycin C [20], gemcitabine [20], paclitaxel [21], interferon- $a_{2 B}$ [22], valrubicin [23], apaziquone [24] and several other agents have been studied in this context, and all have been found to be suboptimal in their ability to prevent disease recurrence and progression. Methods of improving the delivery of these agents have therefore been investigated and device-assisted instillation methods such as electromotive administration and hyperthermia have been the most successful $[9,25]$. Bladder hyperthermia can be achieved in several ways but the intravesical radiofrequency antenna catheter (i.e. the Synergo device) has been the most studied method to date [26].

In this clinical trial we explored a novel method of performing bladder hyperthermia in conjunction with intravesical MMC: external deep pelvic hyperthermia. To obtain external deep pelvic hyperthermia we used a BSD-2000 hyperthermia device and through a process of thermal modelling and clinical dosimetry were able to develop a method of heating the bladder and perivesical tissue that was highly reproducible [6]. Additionally, we found this method of hyperthermia to be associated with not only low toxicity rates but the absence of any serious (grade 3 or higher) treatment-induced toxicity. Advantages of external deep pelvic hyperthermia over other methods of hyperthermia include the ability to heat not only the bladder but the perivesical fat and pelvic lymph nodes, the ability to image the temperature distribution within the pelvis using 3D MR Sigma Eye thermometry, the avoidance of bladder hot spots and urothelial burns, and the ability to steer the temperature distribution and account for variant pelvic anatomy. This means that using the BSD-2000 we can mould the delivery of hyperthermia to the precise anatomical structures of each individual patient. Disadvantages of external deep pelvic hyperthermia include a relatively high start-up equipment cost (approximately US $\$ 500000$ ), difficulties in treating very obese $\left(\mathrm{BMI}>40 \mathrm{~kg} / \mathrm{m}^{2}\right.$ ) patients, and the requirement of maintaining an awake supine position within a constricting water-bolus aperture. Nevertheless, the procedure was generally welltolerated by patients and our results seemed encouraging, particularly since no patient has progressed to muscle invasion thus far and several patients have noted a significant reduction in the frequency of their tumour recurrences. Clinical trials of other forms of hyperthermia combined with MMC have shown an average relative risk reduction (when compared to MMC alone) of $41 \%$ [9]. Additionally, progression rates in these studies ranged from 0 to $8 \%$ [9]. We therefore feel that the current hyperthermia technology merits careful consideration, particularly with respect to the application of novel heat-activated therapies that might be systemically delivered and targeted to bladder and lymph nodes. 


\section{Conclusions}

External deep pelvic hyperthermia using the BSD-2000 device is a safe and reproducible method of heating the bladder in patients undergoing intravesical therapy with mitomycin $\mathrm{C}$ for NMIBC. The efficacy of this treatment modality should be explored further in clinical trials.

\section{References}

1. Siegel R, Naishadham D, Jemal A. Cancer statistics, 2012. CA Cancer J Clin. 2012; 62:10-29. [PubMed: 22237781]

2. Edge, SB.; Byrd, DR.; Compton, CC.; Fritz, AG.; Greene, FL.; Trotti, A. AJCC Cancer Staging Handbook. 7. New York: Springer; 2010.

3. Abern MR, Owusu RA, Anderson MR, Rampersaud EN, Inman BA. Perioperative intravesical chemotherapy in non-muscle-invasive bladder cancer: A systematic review and meta-analysis. J Natl Compr Canc Netw. 2013; 11:477-84. [PubMed: 23584348]

4. Malmstrom PU, Sylvester RJ, Crawford DE, Friedrich M, Krege S, Rintala E, et al. An individual patient data meta-analysis of the long-term outcome of randomised studies comparing intravesical mitomycin $\mathrm{C}$ versus bacillus Calmette-Guerin for non-muscle-invasive bladder cancer. Eur Urol. 2009; 56:247-56. [PubMed: 19409692]

5. Gofrit ON, Shapiro A, Pode D, Sidi A, Nativ O, Leib Z, et al. Combined local bladder hyperthermia and intravesical chemotherapy for the treatment of high-grade superficial bladder cancer. Urology. 2004; 63:466-71. [PubMed: 15028439]

6. Yuan Y, Cheng KS, Craciunescu OI, Stauffer PR, Maccarini PF, Arunachalam K, et al. Utility of treatment planning for thermo-chemotherapy treatment of nonmuscle invasive bladder carcinoma. Med Phys. 2012; 39:1170-81. [PubMed: 22380348]

7. Salahi S, Maccarini PF, Rodrigues DB, Etienne W, Landon CD, Inman BA, et al. Miniature microwave applicator for murine bladder hyperthermia studies. Int J Hyperthermia. 2012; 28:45665. [PubMed: 22690856]

8. Falk MH, Issels RD. Hyperthermia in oncology. Int J Hyperthermia. 2001; 17:1-18. [PubMed: 11212876]

9. Lammers RJ, Witjes JA, Inman BA, Leibovitch I, Laufer M, Nativ O, et al. The role of a combined regimen with intravesical chemotherapy and hyperthermia in the management of non-muscleinvasive bladder cancer: A systematic review. Eur Urol. 2011; 60:81-93. [PubMed: 21531502]

10. van der Zee J, Gonzalez Gonzalez D, van Rhoon GC, van Dijk JD, van Putten WL, Hart AA. Comparison of radiotherapy alone with radiotherapy plus hyperthermia in locally advanced pelvic tumours: A prospective, randomised, multicentre trial. Dutch Deep Hyperthermia Group. Lancet. 2000; 355:1119-25. [PubMed: 10791373]

11. Au JL, Badalament RA, Wientjes MG, Young DC, Warner JA, Venema PL, et al. Methods to improve efficacy of intravesical mitomycin C: Results of a randomized phase III trial. J Natl Cancer Inst. 2001; 93:597-604. [PubMed: 11309436]

12. van der Heijden AG, Kiemeney LA, Gofrit ON, Nativ O, Sidi A, Leib Z, et al. Preliminary European results of local microwave hyperthermia and chemotherapy treatment in intermediate or high risk superficial transitional cell carcinoma of the bladder. Eur Urol. 2004; 46:65-71. discussion 71-2. [PubMed: 15183549]

13. Colombo R, Da Pozzo LF, Salonia A, Rigatti P, Leib Z, Baniel J, et al. Multicentric study comparing intravesical chemotherapy alone and with local microwave hyperthermia for prophylaxis of recurrence of superficial transitional cell carcinoma. J Clin Oncol. 2003; 21:42706. [PubMed: 14581436]

14. Epstein JI, Amin MB, Reuter VR, Mostofi FK. The World Health Organization/International Society of Urological Pathology consensus classification of urothelial (transitional cell) neoplasms of the urinary bladder. Bladder Consensus Conference Committee. Am J Surg Pathol. 1998; 22:1435-48. [PubMed: 9850170] 
15. Gooley TA, Leisenring W, Crowley J, Storer BE. Estimation of failure probabilities in the presence of competing risks: New representations of old estimators. Stat Med. 1999; 18:695-706. [PubMed: $10204198]$

16. R Core Team. R: A Language and Environment for Statistical Computing. Vienna: R Foundation for Statistical Computing; 2013.

17. Sylvester RJ, van der Meijden AP, Oosterlinck W, Witjes JA, Bouffioux C, Denis L, et al. Predicting recurrence and progression in individual patients with stage Ta T1 bladder cancer using EORTC risk tables: A combined analysis of 2596 patients from seven EORTC trials. Eur Urol. 2006; 49:466-77. [PubMed: 16442208]

18. Witjes JA. Management of BCG failures in superficial bladder cancer: A review. Eur Urol. 2006; 49:790-7. [PubMed: 16464532]

19. Isbarn H, Jeldres C, Zini L, Perrotte P, Baillargeon-Gagne S, Capitanio U, et al. A population based assessment of perioperative mortality after cystectomy for bladder cancer. J Urol. 2009; 182:70-7. [PubMed: 19447427]

20. Addeo R, Caraglia M, Bellini S, Abbruzzese A, Vincenzi B, Montella L, et al. Randomized phase III trial on gemcitabine versus mitomycin in recurrent superficial bladder cancer: Evaluation of efficacy and tolerance. J Clin Oncol. 2010; 28:543-8. [PubMed: 19841330]

21. McKiernan JM, Barlow LJ, Laudano MA, Mann MJ, Petrylak DP, Benson MC. A phase I trial of intravesical nanoparticle albumin-bound paclitaxel in the treatment of bacillus Calmette-Guerin refractory nonmuscle invasive bladder cancer. J Urol. 2011; 186:448-51. [PubMed: 21680003]

22. Joudi FN, Smith BJ, O'Donnell MA. Final results from a national multicenter phase II trial of combination bacillus Calmette-Guerin plus interferon alpha-2B for reducing recurrence of superficial bladder cancer. Urol Oncol. 2006; 24:344-8. [PubMed: 16818189]

23. Steinberg G, Bahnson R, Brosman S, Middleton R, Wajsman Z, Wehle M. Efficacy and safety of valrubicin for the treatment of bacillus Calmette-Guerin refractory carcinoma in situ of the bladder. Valrubicin Study Group. J Urol. 2000; 163:761-7. [PubMed: 10687972]

24. Hendricksen K, Cornel EB, de Reijke TM, Arentsen HC, Chawla S, Witjes JA. Phase 2 study of adjuvant intravesical instillations of apaziquone for high risk nonmuscle invasive bladder cancer. $\mathbf{J}$ Urol. 2012; 187:1195-9. [PubMed: 22335860]

25. Di Stasi SM, Valenti M, Verri C, Liberati E, Giurioli A, Leprini G, et al. Electromotive instillation of mitomycin immediately before transurethral resection for patients with primary urothelial nonmuscle invasive bladder cancer: A randomised controlled trial. Lancet Oncol. 2011; 12:871-9. [PubMed: 21831711]

26. Colombo R, Salonia A, Leib Z, Pavone-Macaluso M, Engelstein D. Long-term outcomes of a randomized controlled trial comparing thermochemotherapy with mitomycin-C alone as adjuvant treatment for non-muscle-invasive bladder cancer (NMIBC). BJU Int. 2011; 107:912-8. [PubMed: 21029314] 

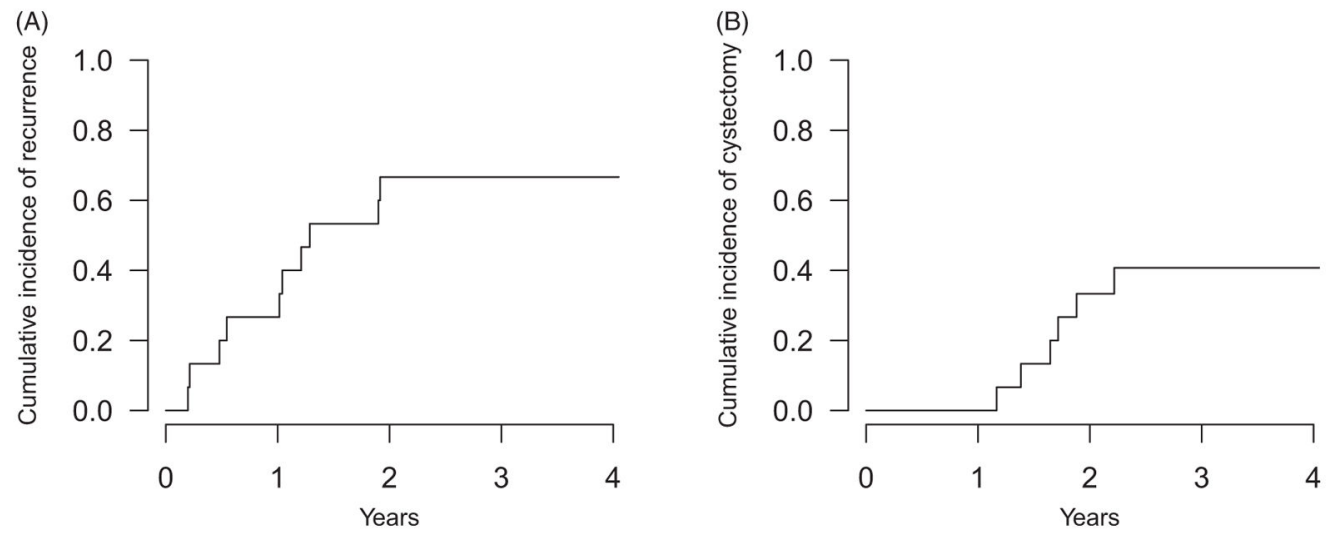

Figure 1.

(A) Cumulative incidence of recurrent bladder cancer and (B) cumulative incidence of radical cystectomy in patients with BCGrefractory NMIBC undergoing intravesical mitomycin $\mathrm{C}$ chemotherapy combined with deep regional pelvic hyperthermia. 


\section{Table I}

Baseline clinical characteristics of the study population.

\begin{tabular}{|c|c|c|}
\hline \multicolumn{3}{|l|}{ Gender } \\
\hline Male & 13 & $87 \%$ \\
\hline Female & 2 & $13 \%$ \\
\hline Age (median) & 66 & IQR: $56.5-75.0$ \\
\hline \multicolumn{3}{|l|}{ ECOG performance status } \\
\hline 0 & 10 & $67 \%$ \\
\hline 1 & 5 & $33 \%$ \\
\hline Charlson score (median) & 3 & IQR: 2-3.5 \\
\hline \multicolumn{3}{|l|}{ Smoking history } \\
\hline Current or former smoker & 11 & $73 \%$ \\
\hline Pack-years exposure ${ }^{l}$ (median number) & 34 & IQR: $3-60$ \\
\hline \multicolumn{3}{|l|}{ Urothelial carcinoma history } \\
\hline Prior recurrences (median number) & 3 & IQR: 3-5 \\
\hline Prior CIS & 11 & $73 \%$ \\
\hline Prior T1 tumour & 4 & $27 \%$ \\
\hline Prior high grade tumour & 8 & $53 \%$ \\
\hline Prior urethral tumour & 1 & $7 \%$ \\
\hline Prior upper tract tumour & 1 & $7 \%$ \\
\hline \multicolumn{3}{|l|}{ EORTC recurrence score } \\
\hline Median & 6 & IQR: 5-8 \\
\hline 0 (low risk) & 0 & $0 \%$ \\
\hline 1-4 (intermediate risk) & 2 & $13 \%$ \\
\hline 5-9 (high risk) & 11 & $73 \%$ \\
\hline 10-17 (very high risk) & 2 & $13 \%$ \\
\hline \multicolumn{3}{|l|}{ EORTC progression score } \\
\hline Median & 8 & IQR: 7-14 \\
\hline $0-1$ (low risk) & 0 & $0 \%$ \\
\hline 2-6 (intermediate risk) & 3 & $20 \%$ \\
\hline 7-13 (high risk) & 8 & $53 \%$ \\
\hline 14-23 (very high risk) & 4 & $27 \%$ \\
\hline \multicolumn{3}{|l|}{ Prior intravesical therapy } \\
\hline BCG doses (median number) & 9 & IQR: 6-12 \\
\hline Mitomycin C & 1 & $7 \%$ \\
\hline Vicinium (VB4-845) clinical trial & 1 & $7 \%$ \\
\hline
\end{tabular}

IQR, interquartile range.

1 Only subjects with a smoking history are included in this calculation. 


\section{Table II}

Treatment-associated adverse events.

\begin{tabular}{|c|c|c|c|}
\hline Adverse event category & Grade 1 & Grade 2 & Total \\
\hline \multicolumn{4}{|l|}{ General } \\
\hline Abdominal pain & $3(20 \%)$ & $2(13 \%)$ & $5(33 \%)$ \\
\hline Fatigue & $2(13 \%)$ & - & $2(13 \%)$ \\
\hline Heat intolerance & - & $1(7 \%)$ & $1(7 \%)$ \\
\hline Myalgia & $1(7 \%)$ & - & $1(7 \%)$ \\
\hline \multicolumn{4}{|l|}{ Genitourinary } \\
\hline Urethral pain & $6(40 \%)$ & - & $6(40 \%)$ \\
\hline Chemical cystitis & $1(7 \%)$ & $3(20 \%)$ & $4(27 \%)$ \\
\hline Haematuria & $3(20 \%)$ & - & $3(20 \%)$ \\
\hline Bladder spasm & $1(7 \%)$ & $1(7 \%)$ & $2(13 \%)$ \\
\hline Weak urinary stream & $1(7 \%)$ & - & $1(7 \%)$ \\
\hline Vaginitis & - & $1(7 \%)$ & $1(7 \%)$ \\
\hline \multicolumn{4}{|l|}{ Gastrointestinal } \\
\hline Nausea or vomiting & $1(7 \%)$ & $1(7 \%)$ & $2(13 \%)$ \\
\hline Constipation & $1(7 \%)$ & - & $1(7 \%)$ \\
\hline \multicolumn{4}{|l|}{ Dermatologic } \\
\hline Induration/swelling & $2(7 \%)$ & $2(13 \%)$ & $4(27 \%)$ \\
\hline Pruritis & $3(20 \%)$ & - & $3(20 \%)$ \\
\hline Rash & $2(13 \%)$ & - & $2(13 \%)$ \\
\hline Bruising & - & $1(7 \%)$ & $1(7 \%)$ \\
\hline Flushing & $1(7 \%)$ & - & $1(7 \%)$ \\
\hline \multicolumn{4}{|l|}{ Neurologic } \\
\hline Dizziness & $2(13 \%)$ & - & $2(13 \%)$ \\
\hline Confusion & - & $1(7 \%)$ & $1(7 \%)$ \\
\hline Anxiety & $1(7 \%)$ & - & $1(7 \%)$ \\
\hline Extrapyramidal symptoms & $1(7 \%)$ & - & $1(7 \%)$ \\
\hline \multicolumn{4}{|l|}{ Infectious } \\
\hline Urinary tract infection & - & $2(13 \%)$ & $2(13 \%)$ \\
\hline \multicolumn{4}{|l|}{ Cardiovascular } \\
\hline Hypertension & $3(20 \%)$ & - & $3(20 \%)$ \\
\hline
\end{tabular}

No grade 3 or higher complications were observed. 